\title{
Exploration and practice of open experimental teaching innovation model in colleges and universities based on "Internet+"
}

\author{
Yang Bo ${ }^{a}$, Yang Mei fang ${ }^{b^{*}}$ \\ Experiment teaching Centre, School of Information Management, Jiang Xi University of Finance \& \\ Economics, Nan Chang 330013 \\ ayb_h@@163.com, b953609701@qq.com
}

Keywords: Open experiment project; Experiment teaching innovation model; Internet+

\begin{abstract}
In this article, through exploring the Internet technology and the network resources, fully meet the demand of experimental teaching reform, build innovation mode of open experimental teaching based on "Internet +", And in innovation opening experiment project of the experimental teaching reform practice has obtained the good effect in Jiangxi university of Finance \& Economics. The model fully embodies the experimental teaching idea of the "take the student as the main body, raises the practice innovation ability as the goal" , To improve the quality of experimental teaching in colleges and universities, For experimental teaching reform and innovation of colleges and universities under the "internet+" environment provide the beneficial reference and enlightenment.
\end{abstract}

\section{Introduction}

"Internet + " is the new formats of Internet development under the background of innovation 2.0, is the Internet form evolution and new forms of the economic and social development driven by knowledge innovation 2.0.Traditional industries have startup "Internet +" mode, such as Internet manufacturing, financial, Internet medical treatment, the Internet transportation and occurrence and development of emerging industries or forms .Experimental teaching in colleges and universities is an important part to cultivate talents which have comprehensive quality and creative ability, with deepening reform of higher education, experiment teaching is faced with upgrading and reform, innovation mode of the experiment teaching based on the Internet has become an urgent requirement.

\section{2. "Internet +" on the Influence of Open Experimental Teaching}

In the "Internet + " environment, especially the development of mobile Internet technology and widely used for the open experiment teaching provides a new technical means of support. The experimental teaching plays an irreplaceable role in training students' innovative spirit and practical ability, because of the economic management course is broad, strong dynamic, traditional teaching methods can't provide complete and dynamic environment, in the face of economy and management laboratory has the characteristics of complexity, dynamic, long time, the experimental teaching mode of traditional dependency theory course hindered the cultivation of innovative talents of management professional disciplines. Using the combination of multimedia computer technology, mobile Internet technology and virtual reality technology, build teaching experiment of administration and management platform based on the Internet cloud platform, realizes the open simulation experiment of administration, fully embodies the significance of the Internet resources and technology in experimental teaching innovation mode and reform. In this article, through full use of Internet resources and technology as the support, with an open innovation experimental project as the breakthrough point of experimental teaching reform of Jiangxi university of finance and economic, exploration and practice opening experimental teaching innovation mode based on the "Internet +". 


\section{Innovation and Practice of Open Experiment Teaching Mode Under the Environment of "Internet +"}

In the "Internet +" environment, is put forward open experiment teaching mode which is support to cloud simulation experiment platform based on multimedia demonstration system and web, open experimental teaching and management platform based on the mobile platform and virtual laboratory. As shown in figure 1.

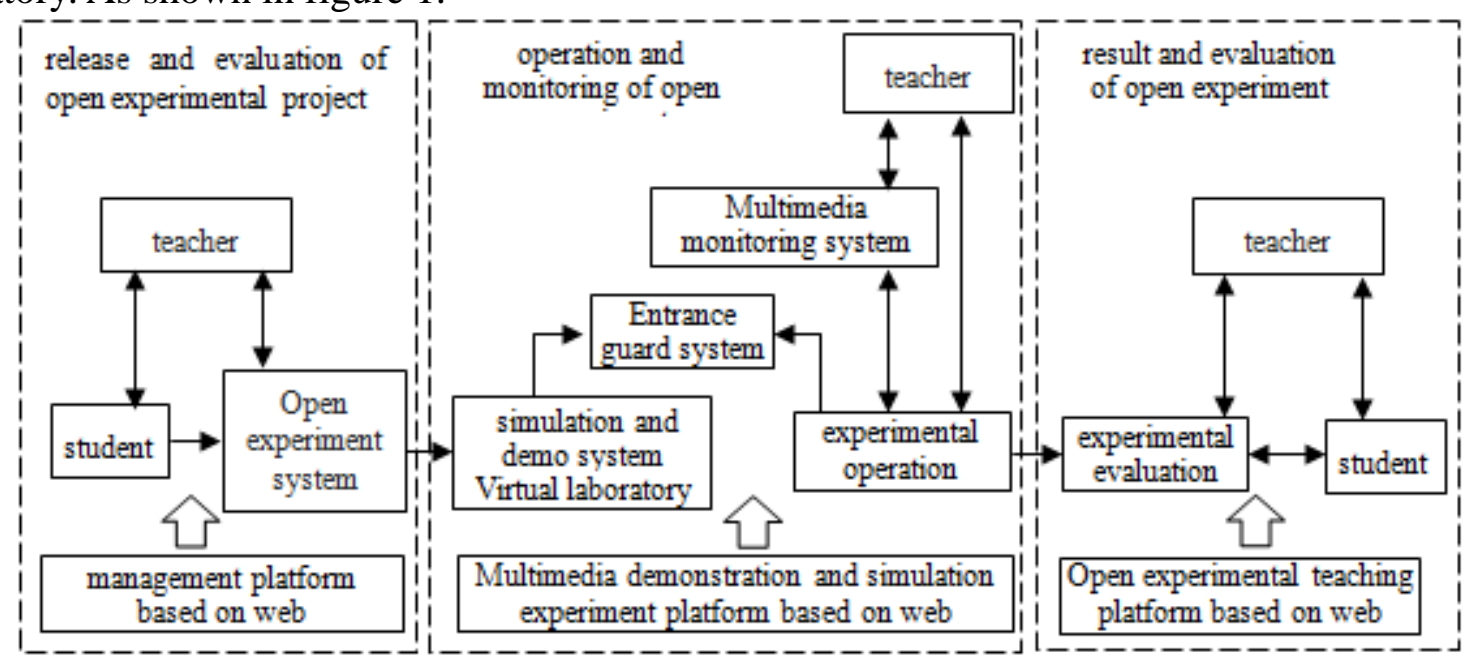

Fig. 1 Open Experimental Teaching Model Based On Internet +

The model is divided into three stages, release and evaluation of open experimental project, Operation and monitoring of open experiment, results and evaluation of open experiments, Respectively support by open experimental teaching (project) management system based on the web under the Internet + environment, multimedia demonstration and simulation experiment system, multimedia monitoring system as well as the open experiment teaching evaluation system based on web.

First Stage: release and evaluation of open experimental project

College experiment center collect the open experiment project from teachers and experts of university-enterprise cooperation unit by opening experiment teaching and management platform, and after examination by the college experimental teaching steering committee, college experiment center published projects to open experiment project management platform.

Project is settings for the three categories, include fundamental experiment, comprehensive design experiment and open exploratory experiment. Open experiment project management platform are set up corresponding class for each type of open projects, and registration credit in the form of practice and innovation course, open projects credited to the student's extracurricular quality expanding credit, solve the problems of the students credits and teachers' workload. Through the open experiment teaching and management platform, students submit open experiment project application, and according to the requirements of the selected experimental project, submit relevant documents. At the same time, management platform push project choice information to teachers automatically, selection of open experiment project is complete after guiding teacher confirmed. Release and evaluation of open experiment project mode as shown in figure 2. 


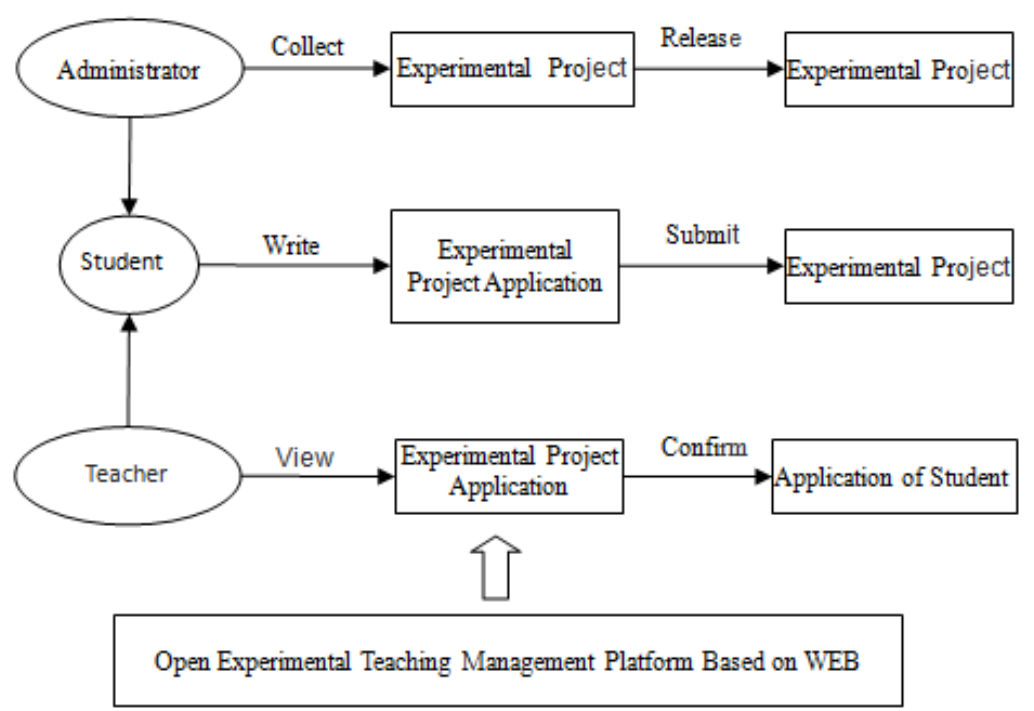

Fig. 2 Release and evaluation of open experiment project mode

Second Stage: Stage of open experiment project operation and monitoring

For open experiments project which can simulate in experiment platform, after teacher authorized, students can enter the network virtual laboratory. Using the multimedia presentation of virtual laboratory system and experimental simulation platform, students can operate established experiment project. For the practical experiment project, students can simulate through interactive multimedia experiment courseware, such as accounting, financial projects; For application and design experiment, can restore and simulate through virtual reality scene, such as logistic management, securities investment projects; In this process, Students can ask teacher for help through the platform at any time. Platform record experimental operation process, guidance of teachers and Stage results automatically. Virtual laboratory opening experimental teaching mode as shown in figure 3.

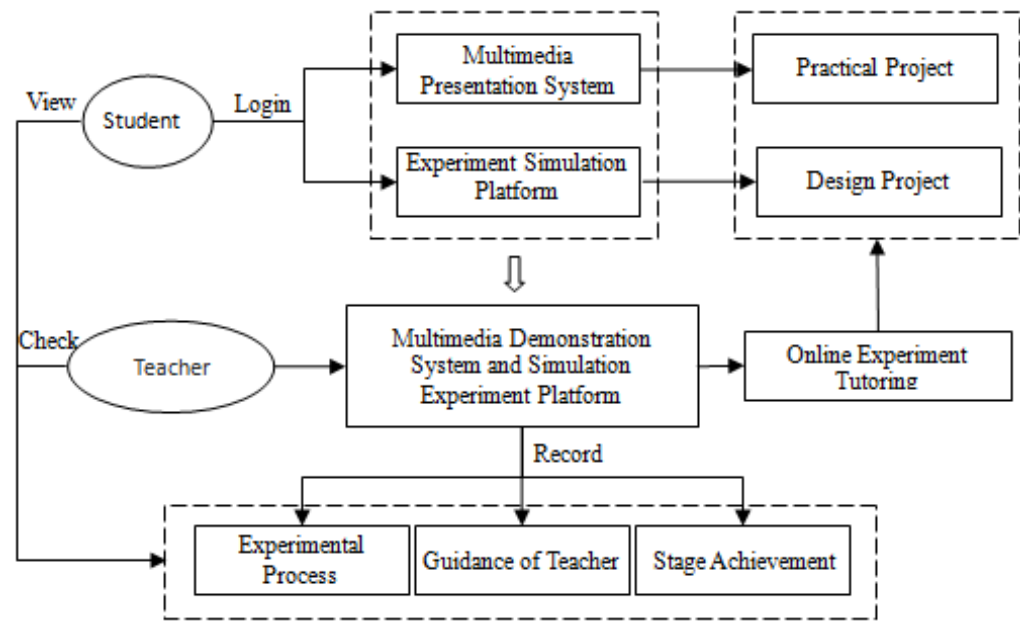

Fig. 3 Virtual laboratory open experiment teaching pattern

For open experiments project which can't simulate in laboratory, students can make an appointment to laboratory on management platform. Students can operate laboratory through the mobile or PC on the platform, at the same time, management platform release confirmation request to open project guidance teachers, after the tutor confirm, students can according to the appointments and laboratory. After using campus card for identification and confirmation through the lab entrance guard system, students can enter the reservation laboratory to operate the experiment project. For experiment project based on the course which don't complete within experiment teaching plan, students can choose opening experiment project again. Because of long period of innovation and customize open projects, in the whole experiment process, teachers can't participate in laboratory instruction, most of the time is complete by student themselves. Using the laboratory multimedia real-time monitoring system, it can solve the problem of separation of 
teachers and students in the process of experiment and the asynchronous guidance. Teachers can supervise and control students' experiment process in real-time or non real-time through this system, teacher can solve the problems timely encountered during the experiment, and backup audio and video data. For various problems in the process of operation, teachers and students can communicate with each other through the system of the instant communication function module and audio and video interaction system based on mobile or using third-party Internet instant messaging tools (such as telephone, QQ, We Chat, email) and so on a variety of ways . Opening experimental teaching mode of booking laboratory as shown in figure 4.

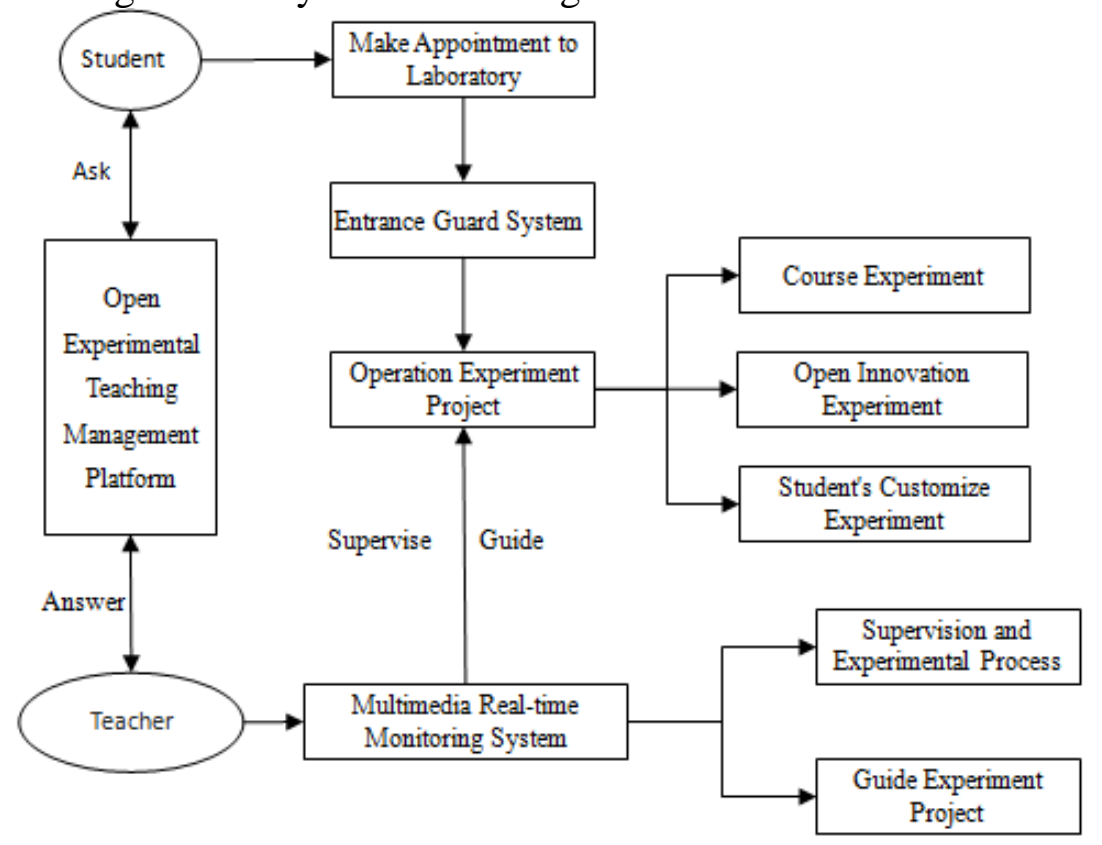

Fig. 4 opening experimental teaching mode of booking laboratory

Third Stage: results and evaluation of open experiment phase

After students complete the experiment project, student upload the test report and related project work to the management platform. Teachers evaluate completion of student experiment project through the following way:

(1) Log on to the management platform, download and lookup the students' experiment or project report, given the results of the work evaluation and score through the management platform.

(2) Through multimedia real-time monitoring system, check the students' experiment monitoring records, observation student's experimental process, evaluate the experimental process, and gives experimental process points on management platform.

(3) According to the results evaluation and process evaluation to make a final assessment of the project of experiment for students. For evaluation result, students can timely query result and evaluation of the experiment project through management platform, summarizes in a timely manner, at the same time students can evaluate the teacher's guidance, platform will automatically on a regular basis to the students' evaluation, and feedback anonymously through mobile platform to teachers. Evaluation score will be approved as the basis of teacher's experimental teaching work, to promote the further development of open experimental teaching. Open experiment results and evaluation phase mode as shown in figure 5. 


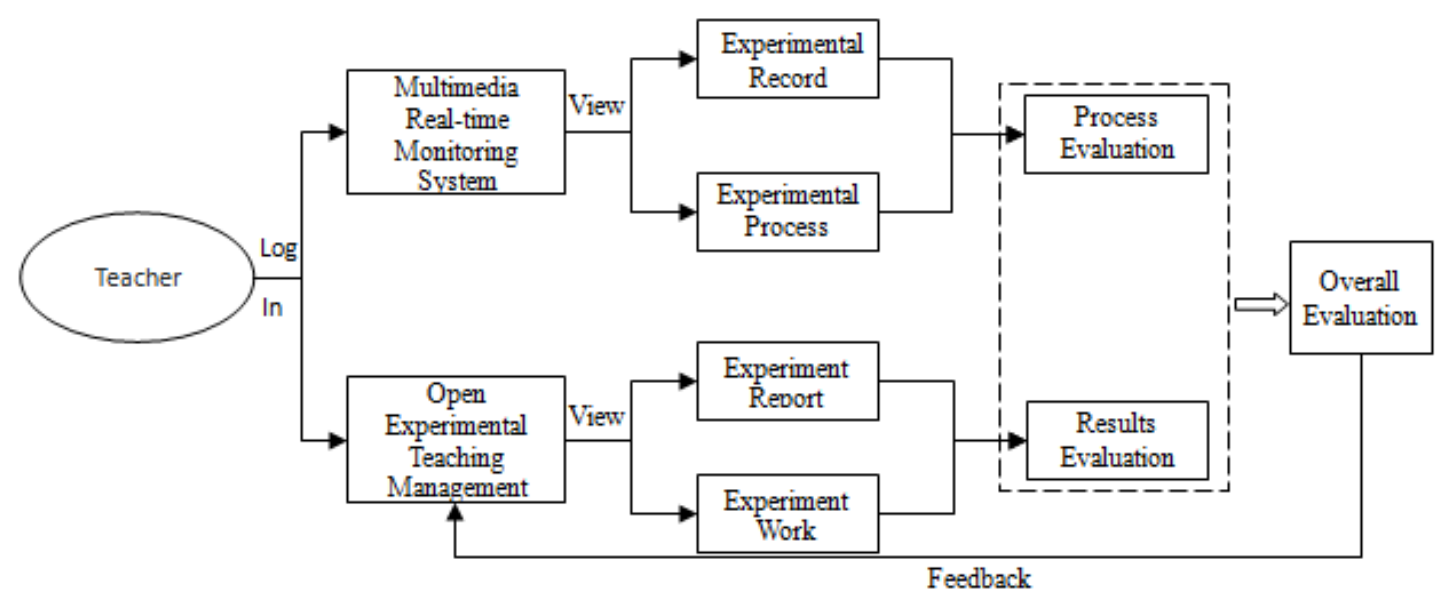

Fig. 5 Open experiment results and evaluation phase mode

The experimental teaching reform of "open innovation experiment project" in Jiangxi university of finance, take students as the main body in teaching, to explore the new way of opening experimental teaching mode. According to the questionnaire survey: In 600 effective samples , carry out experimental teaching mode for the open experiment project based on Internet, 95\% of students believe that improved understanding of theory courses and practical ability, 90\% of students think this mode improved comprehensive ability of applying skills, $92 \%$ of students think this is of great help to Internet start-up, operation and management ability in the future.

\section{Conclusion}

In this article, through exploring that using Internet technology and network resources, fully meet demand of experimental teaching reform, build open experiment teaching innovation mode. In this model, study of opening experiment teaching is still in practice stage. This paper put forward innovation mode of open experimental teaching is depend on Internet technology and equipment under "Internet + " environment, establish main line which is based on students' experiment, to cultivate students' innovative practice ability as breakthrough point. Open innovation experiment in experimental teaching reform practice of project achieved good operating results in Jiang xi university of finance and economics, improved quality of experiment teaching in our school.

\section{Acknowledgements}

This work was financially supported by the degree and postgraduate education teaching reform project in Jiangxi province (JXYJG - 2016-068).

\section{References}

[1] Jing Quan Zhong. The research of innovation teaching mode under the background of "Internet +" [J]. Journal of education research,2015(9):98-100.

[2] Li Hong Chen. Explore and practice the open innovative experiment teaching mode in colleges and universities[J]. Journal of higher education, 2013(5):102-105.

[3] Wen Juan zheng. research management under the new media technology network laboratories [J]. Journal of electronic technology and software engineering,2015(15):26-27.

[4] Li Yan. Experimental teaching system under the open and autonomous learning mode [J]. Journal of laboratory research and exploration,2012,31(1):134-137.

[5] Wang Yi. Construction of the new experimental teaching model based on the creative ability training[J].2011,28(2):16-17.

[6] Li Yan. Experimental teaching system under the open and autonomous learning mode [J]. Journal of laboratory research and exploration,2012,31(1):134-137. 